\title{
Implementation of a Capacitive Discharge Ignition for Dual-cylinder Motorcycles
}

\author{
Jye-Chau Su, ${ }^{1}$ Cheng-Tao Tsai, ${ }^{2 *}$ and Ji-Xin $\mathrm{Chen}^{2}$ \\ ${ }^{1}$ Department of Electronic Engineering, National Chin-Yi University of Technology, \\ No. 57, Sec. 2, Zhongshan Rd., Taiping Dist., Taichung City 41170, Taiwan \\ ${ }^{2}$ Department of Electrical Engineering, National Chin-Yi University of Technology, \\ No. 57, Sec. 2, Zhongshan Rd., Taiping Dist., Taichung City 41170, Taiwan
}

(Received July 24, 2019; accepted November 5, 2019)

Keywords: CDI, dual-cylinder, contact-type, $\mathrm{HC}, \mathrm{CO}$

In this paper, the implementation of a capacitive discharge ignition (CDI) for dualcylinder motorcycles is presented. The structure of the proposed CDI mainly includes one microcontroller, one flyback converter, two capacitive-discharge circuits, and two over-voltage protection circuits. The proposed CDI mainly uses Hall sensors to sense the optimal signal of the ignition time. Therefore, the optimal ignition angle of the spark plugs can be obtained. In comparison with a traditional contact magnetic ignition, the proposed CDI can obtain more exact ignition timing of the spark plugs and reduce hydrocarbons (HC) and carbon monoxide (CO) in the exhausts of motorcycles. Therefore, air pollution is reduced and the environmental quality can be significantly improved. Finally, to verify the performance of the proposed CDI for dual-cylinder motorcycles, a prototype hardware circuit was built and implemented. From the experimental results, the feasibility of the proposed CDI has been verified.

\section{Introduction}

In recent years, the rapid development of economies and vehicles has resulted in the greenhouse effect. The hydrocarbons (HC) and carbon monoxide (CO) emitted from vehicles already account for a quarter of the world's emissions. ${ }^{(1,2)}$ In this society of convenient transportation, motorcycles are indispensable for daily life. Therefore, how to reduce the amounts of $\mathrm{HC}$ and $\mathrm{CO}$ in the exhausted gas emitted from motorcycles has become an important issue. Usually, the ignitions of motorcycles can be divided into two categories: magnetic ignitions and capacitive discharge ignitions (CDIs). ${ }^{(3-6)}$ A magnetic ignition via a speedsignal generator produces two ignition signals of the spark plugs. However, a magnetic ignition has the following disadvantages: 1) its speed signal generator cannot accurately calculate the optimal ignition time, resulting in the deviation of the ignition angle of the spark plugs. 2) When the engine is operated at a high speed, the output voltage of the ignition becomes smaller, which results in the difficulty in ignition by the spark plugs. These phenomena cause the fuel to burn incompletely, which will increase air pollution. According to a technical manual of "Corresponding author: e-mail: cttsai@ncut.edu.tw https://doi.org/10.18494/SAM.2020.2576 
motorcycles, the optimal ignition angle of the spark plugs occurs when the crankshaft angle is $10^{\circ}$ after the top dead point, as shown in Fig. $1 .^{(7-10)}$

To overcome the above disadvantages, a CDI with a microcontroller and Hall sensors to obtain optimal ignition angles of dual-cylinder motorcycles is presented, as shown in Fig. 2. The Hall sensors sense the ignition signal via a microprocessor to calculate the optimal ignition timings of the spark plugs, and thus obtain optimal ignition timings at different speeds of the dual-cylinder engines. ${ }^{(11-13)}$ The structure of the proposed CDI is described in Sect. 2. The operational principles of the proposed CDI are described in Sect. 3. The experimental results obtained from the proposed CDI are presented in Sect. 4. Finally, a conclusion is given in Sect. 5.

\section{Structure of CDI}

The proposed CDI for dual-cylinder motorcycles is shown in Fig. 2 and its block diagram is shown in Fig. 3. In Fig. 2, the voltage of the discharging capacitors $C_{D 1}$ and $C_{D 2}$ is boosted to $150 \mathrm{~V}_{\mathrm{DC}}$ via a flyback converter. After the microcontroller receives a trigger signal from the ignitor, it generates a corresponding trigger signal to turn on the discharging switches $S_{w 1}$ and $\mathrm{S}_{\mathrm{w} 2}$. Thus, the energy stored in $\mathrm{C}_{\mathrm{D} 1}$ and $\mathrm{C}_{\mathrm{D} 2}$ is discharged to the spark plugs via the ignition coils $T_{\mathrm{r} 1}$ and $\mathrm{T}_{\mathrm{r} 2}$. The ignition coils are high-voltage transformers, which boost the voltage of the discharging capacitors (about $25 \mathrm{kV}$ ) to ignite spark plugs 1 and 2.

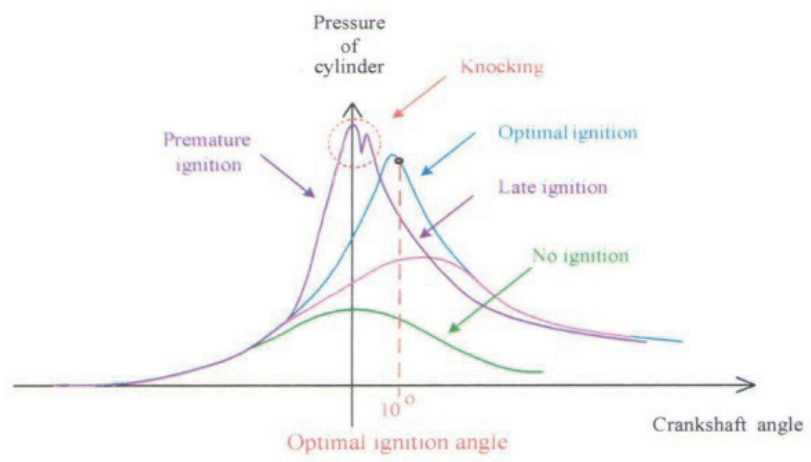

Fig. 1. (Color online) Relationship between cylinder pressure and crankshaft position.

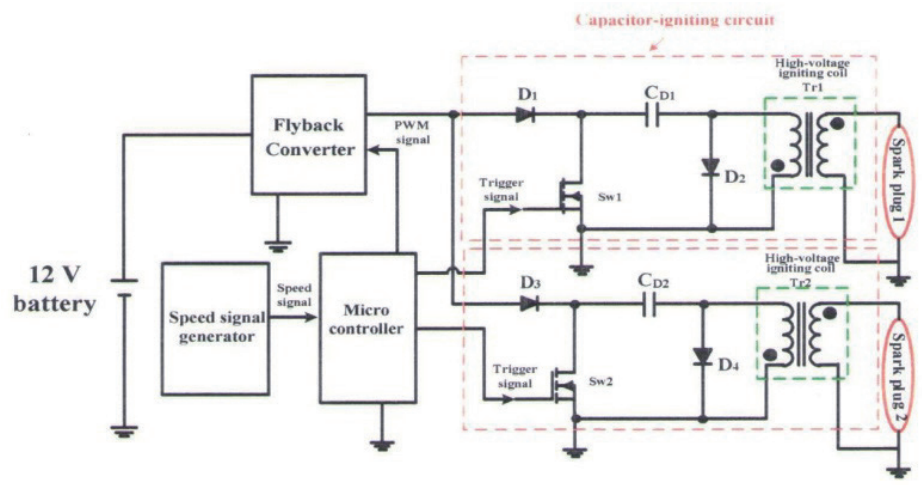

Fig. 2. (Color online) Structure of the proposed CDI for dual-cylinder motorcycles.

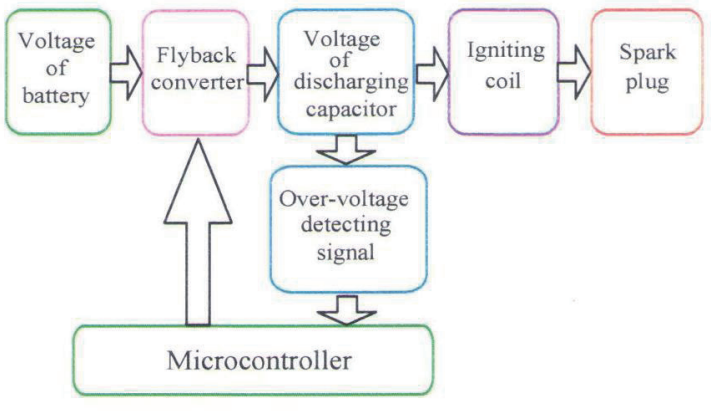

Fig. 3. (Color online) Block diagram illustrating the structure of the proposed CDI. 
According to Fig. 1, the optimal ignition angle of the engine occurs when the crankshaft angle is $10^{\circ}$ after the top dead point. A delay or missing this ignition angle results in a lower cylinder pressure, which leads to more fuel consumption and exhausted gas emission. To obtain an optimal signal at an ignition angle of $10^{\circ}$, a microcontroller combined with software is incorporated into the proposed CDI to detect the engine speed. The control flowchart for the optimal ignition angle is shown in Fig. 4.

\section{Operational Principles}

Figure 5 shows the detailed circuit of the proposed CDI for dual-cylinder motorcycles. The operational principles of the proposed CDI over one switching cycle can be divided into six major operating modes. Figure 6 shows the current and voltage waveform of the key components and the driving signals of the switches $\mathrm{Sw}_{1}$ and $\mathrm{Sw}_{2}$. Figure 7 shows the equivalent circuit modes of the proposed CDI. To simplify the description of the operational modes, the following assumptions are made.

The discharging capacitors $\mathrm{C}_{\mathrm{D} 1}, \mathrm{C}_{\mathrm{D} 2}, \mathrm{C}_{\mathrm{D} 3}$, and $\mathrm{C}_{\mathrm{D} 4}$ are sufficiently large for the voltages across them to be constant over a switching cycle.

All the magnetic components, power switches, and power diodes are ideal.

Mode 1 [Fig. 7(a), $t_{0}<t<t_{1}$ ]:

At time $t_{0}$, the main switch $\mathrm{M}_{1}$ is turned on, and the discharging switches $\mathrm{S}_{\mathrm{w} 1}$ and $\mathrm{S}_{\mathrm{w} 2}$ and the diodes $\mathrm{D}_{1}$ and $\mathrm{D}_{2}$ are turned off. The magnetic current $i_{L m}$ of the transformer $\mathrm{T}_{\mathrm{r}}$ flowing through the path $\mathrm{V}_{\mathrm{s}} \rightarrow \mathrm{L}_{\mathrm{m}} \rightarrow \mathrm{M}_{1}$ is linearly increased. The magnetic current $i_{L m}$ of the transformer $\mathrm{T}_{\mathrm{r}}$ can be expressed as

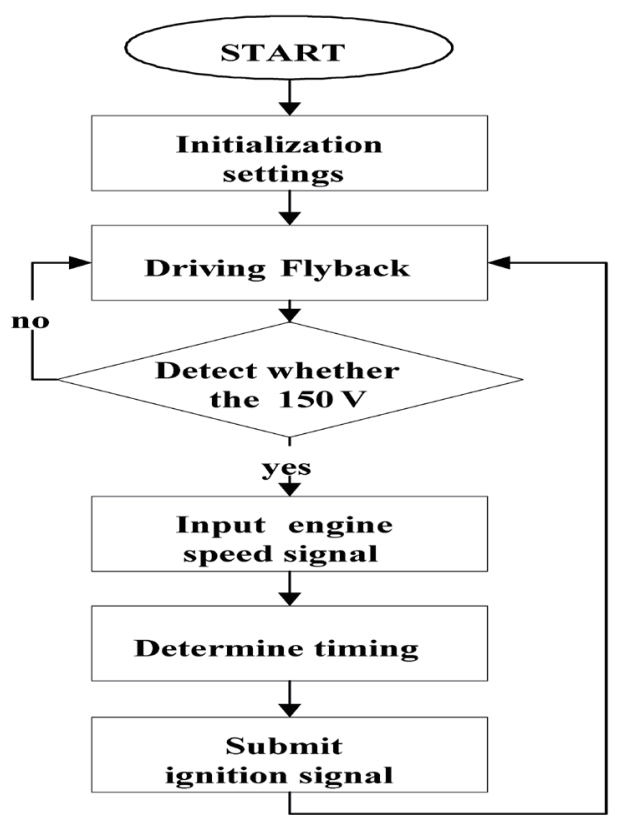

Fig. 4. Control flowchart for the optimal ignition angle. 


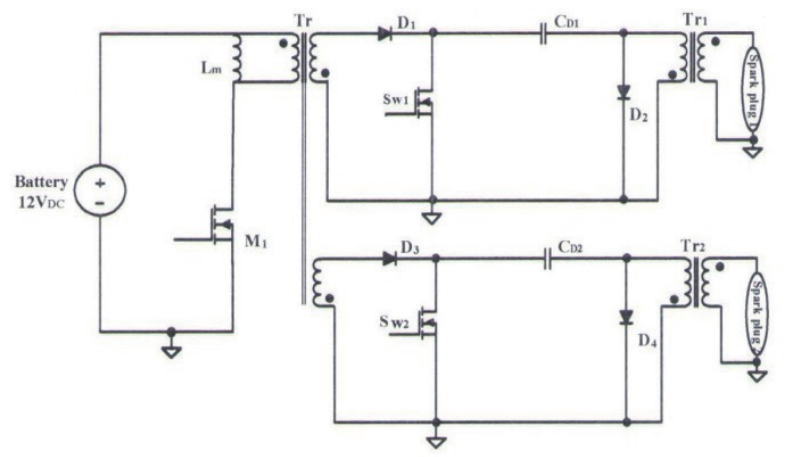

Fig. 5. Detailed circuit of the proposed CDI for dual-cylinder motorcycles.

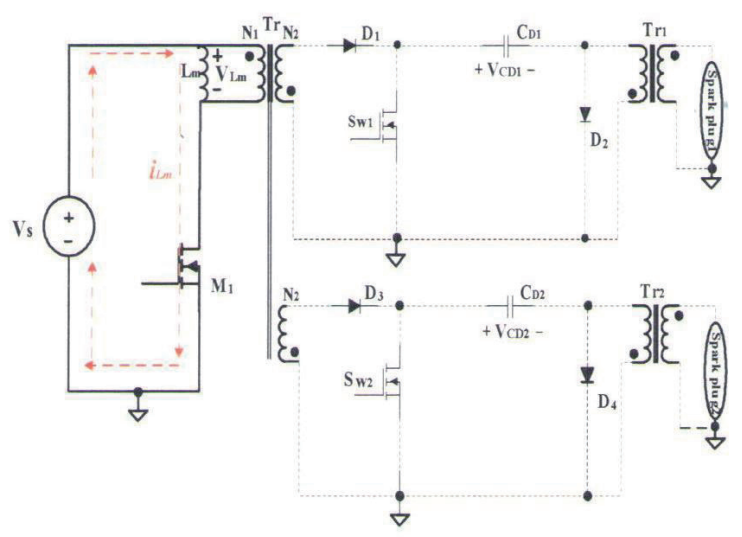

(a)

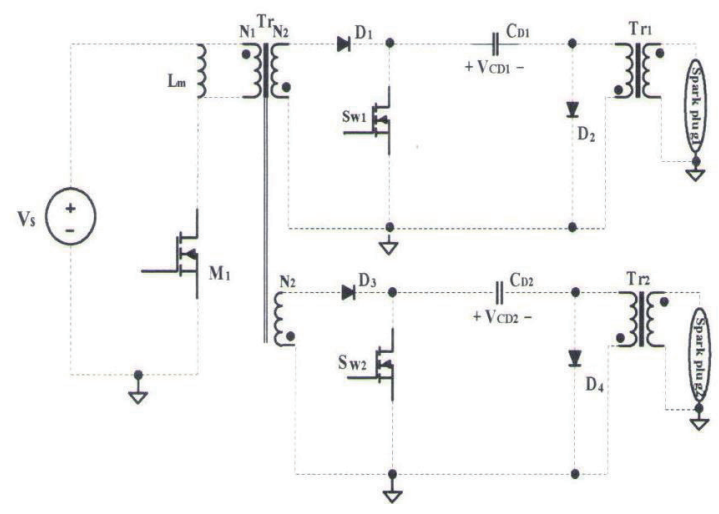

(c)

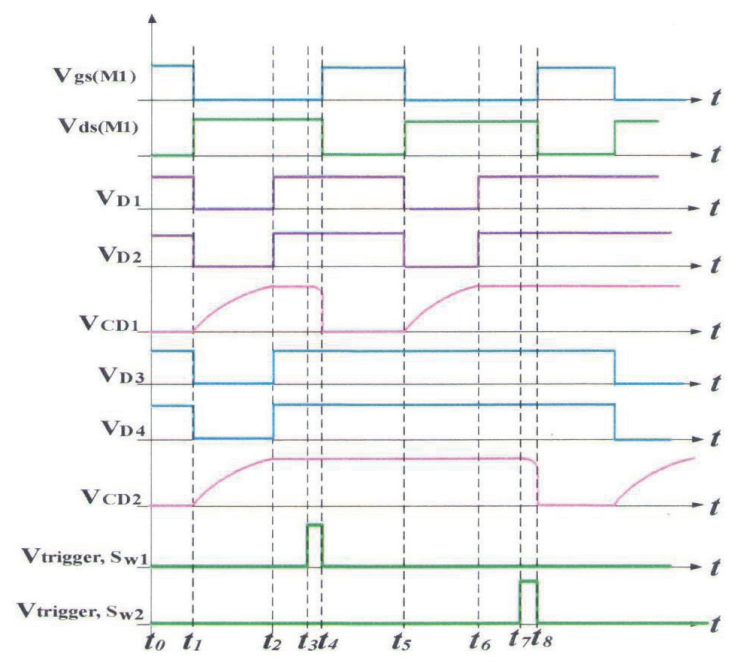

Fig. 6. (Color online) Voltage waveforms of the key components for proposed CDI.

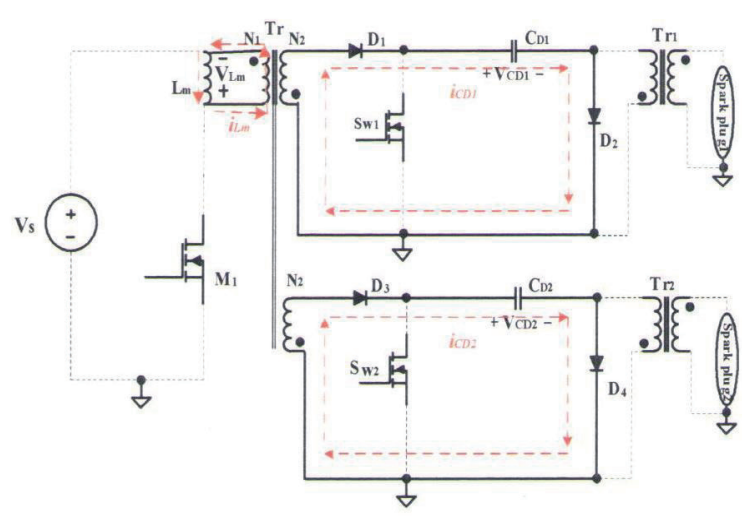

(b)

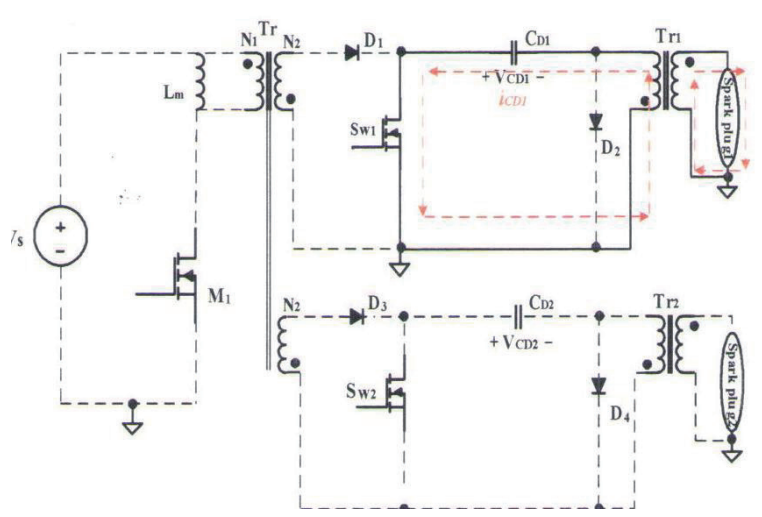

(d)

Fig. 7. (Color online) Equivalent circuits of the proposed CDI for dual-cylinder motorcycles. (a) Mode 1, (b) Mode 2, (c) Mode 3, and (d) Mode 4. 


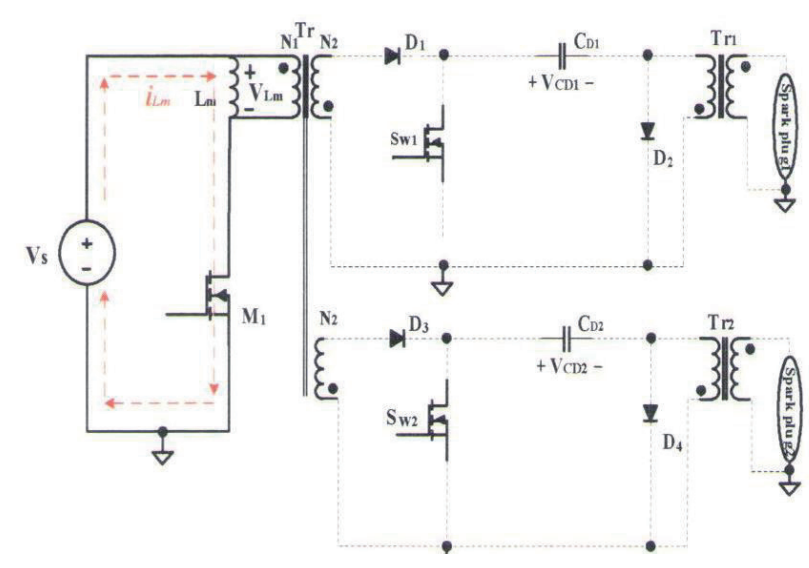

(e)

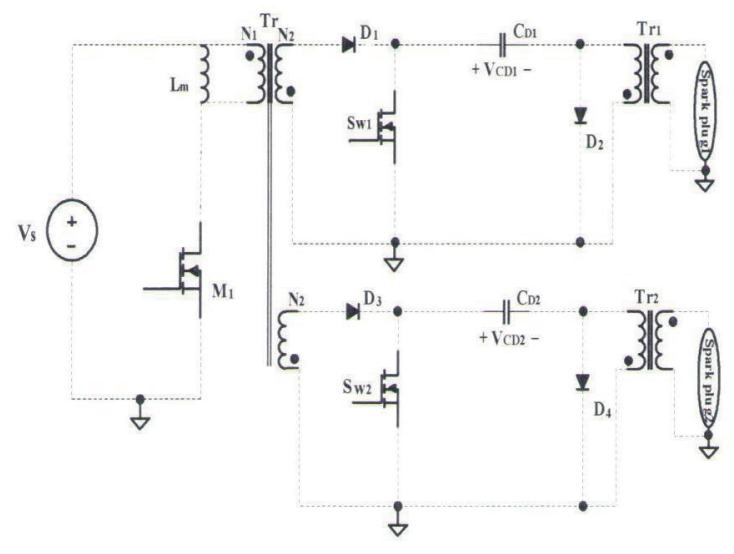

(g)

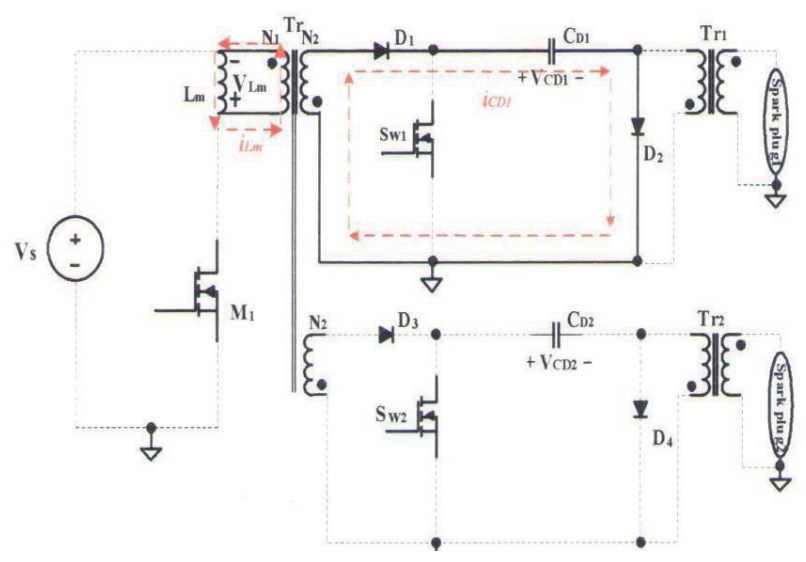

(f)

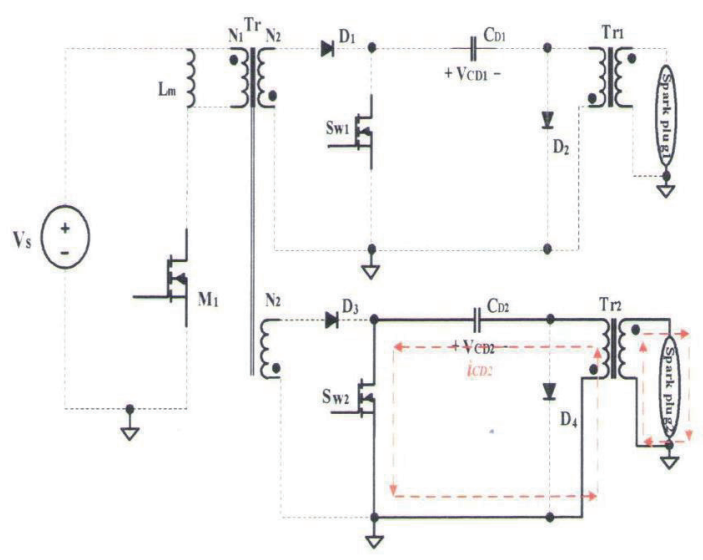

(h)

Fig. 7. (Color online) (Continued) Equivalent circuits of the proposed CDI for dual-cylinder motorcycles. (e) Mode 5, (f) Mode 6, (g) Mode 7, and (h) Mode 8.

$$
i_{L m}(t)=\frac{V_{s}}{L_{m}}\left(t-t_{0}\right)
$$

The equivalent circuit is shown in Fig. 7(a).

Mode 2 [Fig. 7(b), $t_{1}<t<t_{2}$ ]:

At time $t_{1}$, the main switch $\mathrm{M}_{1}$ is turned off, and the discharging switches $\mathrm{S}_{\mathrm{w} 1}$ and $\mathrm{S}_{\mathrm{w} 2}$ and diodes $\mathrm{D}_{1}$ and $\mathrm{D}_{2}$ are turned on. The magnetic current $i_{L m}$ of the transformer $\mathrm{T}_{\mathrm{r}}$ is transferred to the discharging capacitors $\mathrm{C}_{\mathrm{D} 1}$ and $\mathrm{C}_{\mathrm{D} 2}$. The currents $i_{C D 1}$ and $i_{C D 2}$ of the discharging capacitors $\mathrm{C}_{\mathrm{D} 1}$ and $\mathrm{C}_{\mathrm{D} 2}$ are increased and can be expressed as

$$
i_{C D 1}(t)=\frac{1}{C_{D 1}} \int_{t_{1}}^{t_{2}} V_{C D 1} d t
$$


and

$$
i_{C D 2}(t)=\frac{1}{C_{D 2}} \int_{t_{1}}^{t_{2}} V_{C D 2} d t .
$$

The equivalent circuit is shown in Fig. 7(b).

Mode 3 [Fig. 7(c), $t_{2}<t<t_{3}$ ]:

At time $t_{2}$, the main switch $\mathrm{M}_{1}$ is kept turned off. The voltages of the discharging capacitors $\mathrm{C}_{\mathrm{D} 1}$ and $\mathrm{C}_{\mathrm{D} 2}$ are charged to $V_{L m}\left(N_{1} / N_{2}\right)$, and then the diodes $\mathrm{D}_{1}, \mathrm{D}_{2}, \mathrm{D}_{3}$ and $\mathrm{D}_{4}$ are turned off. The equivalent circuit is shown in Fig. 7(c).

Mode 4 [Fig. $7(d), t_{3}<t<t_{4}$ ]:

At time $t_{3}$, the driving signal of the switch $\mathrm{S}_{\mathrm{w} 1}$ is generated, and the discharging capacitor $C_{D 1}$ begins discharging via $S_{w 1}$ and $T_{r 1}$. During this interval, spark plug 1 is rapidly ignited. The equivalent circuit is shown in Fig. 7(d).

Mode 5 [Fig. 7(e), $t_{4}<t<t_{5}$ ]:

At time $t_{4}$, the voltage of the discharged capacitor $\mathrm{C}_{\mathrm{D} 1}$ is dropped to zero, and the driving signal of the switch $S_{w 1}$ is turned off. At this time, the main switch $\mathrm{M}_{1}$ is turned on once again. The magnetic current $i_{L m}$ of the transformer $T_{\mathrm{r}}$ can be expressed as

$$
i_{L m}(t)=\frac{V_{s}}{L_{m}}\left(t_{4}-t_{5}\right)
$$

The equivalent circuit is shown in Fig. 7(e).

Mode 6 [Fig. 7(f), $t_{5}<t<t_{6}$ ]:

At time $t_{5}$, the main switch $\mathrm{M}_{1}$ is turned off, and the discharging switch $\mathrm{S}_{\mathrm{w} 1}$ and the diodes $\mathrm{D}_{1}$ and $\mathrm{D}_{2}$ are turned on. The magnetic current $i_{L m}$ of the transformer $\mathrm{T}_{\mathrm{r}}$ is transferred to the discharging capacitor $\mathrm{C}_{\mathrm{D} 1}$. The current $i_{C D 1}$ of the discharging capacitor $\mathrm{C}_{\mathrm{D} 1}$ is increased, which can be expressed as

$$
i_{C D 1}(t)=\frac{1}{C_{D 1}} \int_{t_{5}}^{t_{6}} V_{C D 1} d t,
$$

The equivalent circuit is shown in Fig. 7(f).

Mode 7 [Fig. $\left.7(\mathrm{~g}), \boldsymbol{t}_{6}<t<t_{7}\right]$ :

At time $t_{6}$, the main switch $\mathrm{M}_{1}$ is kept turned off. The voltage of the discharging capacitor $\mathrm{C}_{\mathrm{D} 1}$ is charged to $V_{L m}\left(N_{1} / N_{2}\right)$, and then the diodes $\mathrm{D}_{1}$ and $\mathrm{D}_{2}$ are turned off. The equivalent circuit is shown in Fig. $7(\mathrm{~g})$.

Mode 8 [Fig. 7(h), $t_{7}<t<t_{8}$ ]:

At time $t_{7}$, the driving signal of the switch $\mathrm{S}_{\mathrm{w} 2}$ is generated, and the discharging capacitor $\mathrm{C}_{\mathrm{D} 2}$ begins discharging via $\mathrm{S}_{\mathrm{w} 2}$ and $\mathrm{T}_{\mathrm{r} 2}$. During this interval, spark plug 2 is rapidly ignited. The equivalent circuit is shown in Fig. $7(\mathrm{~g})$. At time $t_{8}$, the voltage of the discharging capacitor 
$\mathrm{C}_{\mathrm{D} 2}$ drops to zero, and the driving signal of the switch $\mathrm{S}_{\mathrm{w} 2}$ is turned off. At this time, the main switch $\mathrm{M}_{1}$ is turned on once again. The magnetic current $i_{L m}$ of the transformer $T_{\mathrm{r}}$ flowing through the path $\mathrm{V}_{\mathrm{s}} \rightarrow \mathrm{L}_{\mathrm{m}} \rightarrow \mathrm{M}_{1}$ is linearly increased. The magnetic current $i_{L m}$ of the transformer $\mathrm{T}_{\mathrm{r}}$ can be expressed as

$$
i_{L m}(t)=\frac{V_{s}}{L_{m}}\left(t-t_{7}\right)
$$

The equivalent circuit is shown in Fig. 7(h). At this stage, the operational mode of the proposed CDI over one switching cycle is completed.

\section{Experimental Results}

To verify the feasibility of the proposed CDI for dual-cylinder motorcycles, a prototype was built. The specifications and key components are shown in Tables 1 and 2, respectively.

Figure 8 shows an experimental igniting signal, the voltage of the discharging capacitor, and the switching frequency of the main switch waveforms, from which it can be seen that an igniting signal is generated, and the voltage of the discharging capacitor is rapidly reduced to zero. Figure 9 shows experimental voltage waveforms of the discharging capacitors $C_{D 1}$ and $\mathrm{C}_{\mathrm{D} 2}$ operated in the engine speed range of 1000 to $10000 \mathrm{rpm}$, from which it can be seen that the voltages of $C_{D 1}$ and $C_{D 2}$ can easily become $150 \mathrm{~V}$. Figure 10 shows the experimental igniting voltage waveforms of spark plugs 1 and 2 , from which it can be seen that the igniting voltage is

Table 1

Specifications of CDI.

\begin{tabular}{lc}
\hline Input voltage & $12 \mathrm{~V}_{\mathrm{DC}}$ \\
Igniting voltage of spark plug & $25 \mathrm{kV}$ \\
Test speed of engine & $1000-10000 \mathrm{rpm}$ \\
Switching frequency of main switch & $50 \mathrm{kHz}$ \\
\hline
\end{tabular}

Table 2

Key components of CDI.

\begin{tabular}{lc}
\hline Main switch $\mathrm{M}_{1}$ & IRF640 \\
Igniting switches $\mathrm{S}_{\mathrm{w} 1}$ and $\mathrm{S}_{\mathrm{w} 2}$ & R5013ANX \\
Power diodes $\mathrm{D}_{1}, \mathrm{D}_{2}, \mathrm{D}_{3}$, and $\mathrm{D}_{4}$ & US1J \\
Core of transformer $\mathrm{T}_{\mathrm{r}}$ & $\mathrm{RM}-8$ \\
Discharging capacitors $\mathrm{C}_{\mathrm{D} 1}$ and $\mathrm{C}_{\mathrm{D} 2}$ & $2.2 \mu \mathrm{F} / 450 \mathrm{~V}$ \\
Microcontroller & $\mathrm{PIC16F684}$ \\
\hline
\end{tabular}

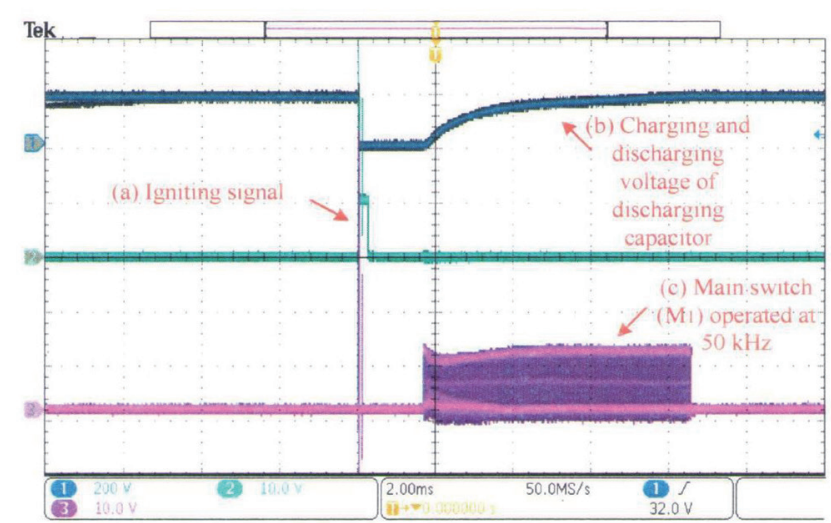

Fig. 8. (Color online) Key waveforms of the proposed CDI: (a) igniting signal of spark plug 1, (b) charging and discharging of capacitor $\mathrm{C}_{\mathrm{D} 1}$, and (c) switching frequency of main switch $\mathrm{M}_{1}$. 


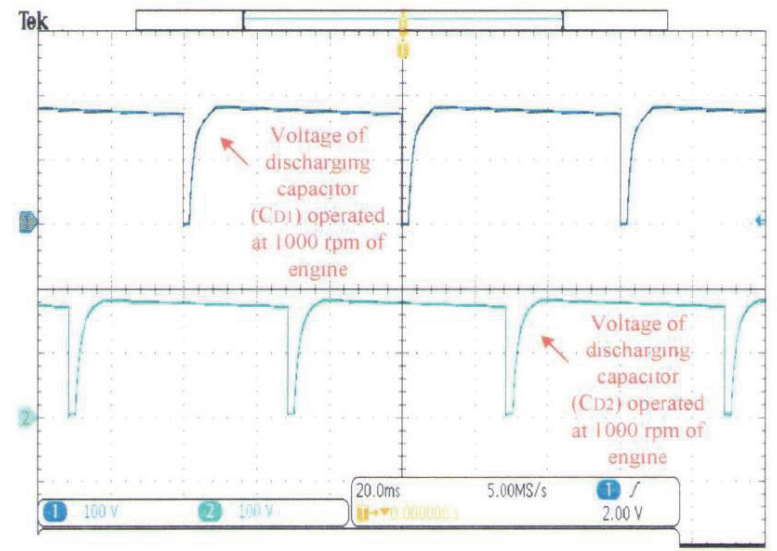

(a)

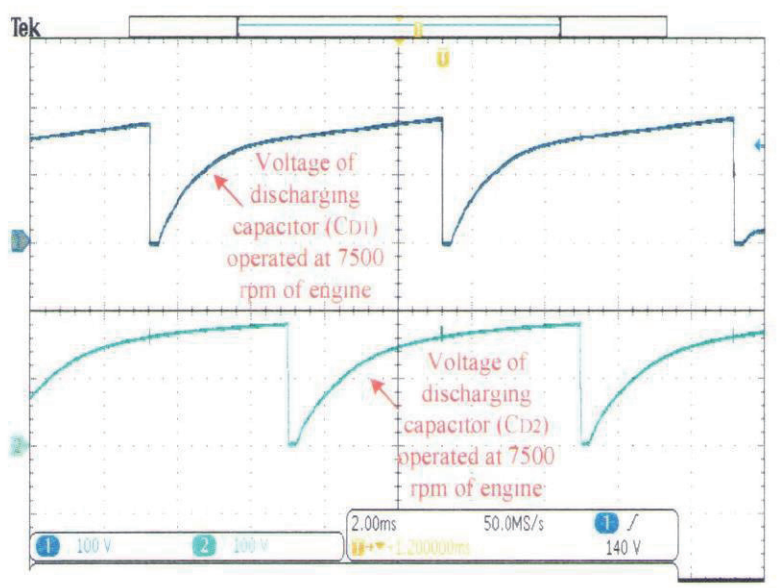

(c)

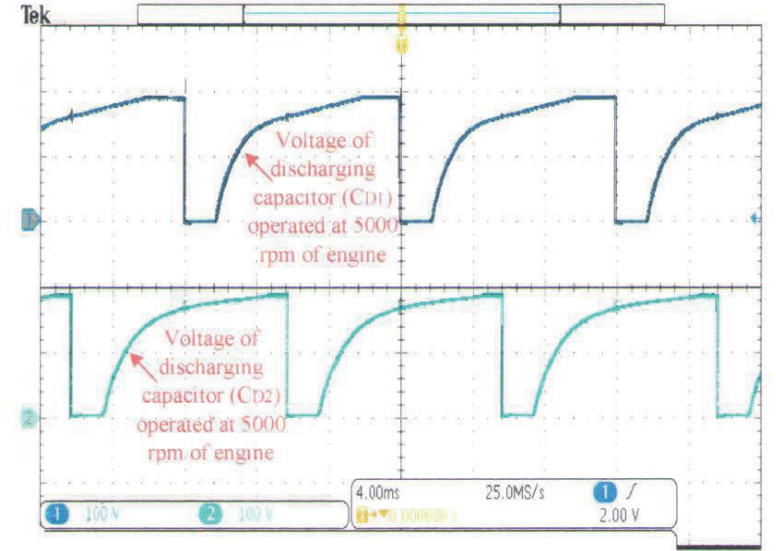

(b)

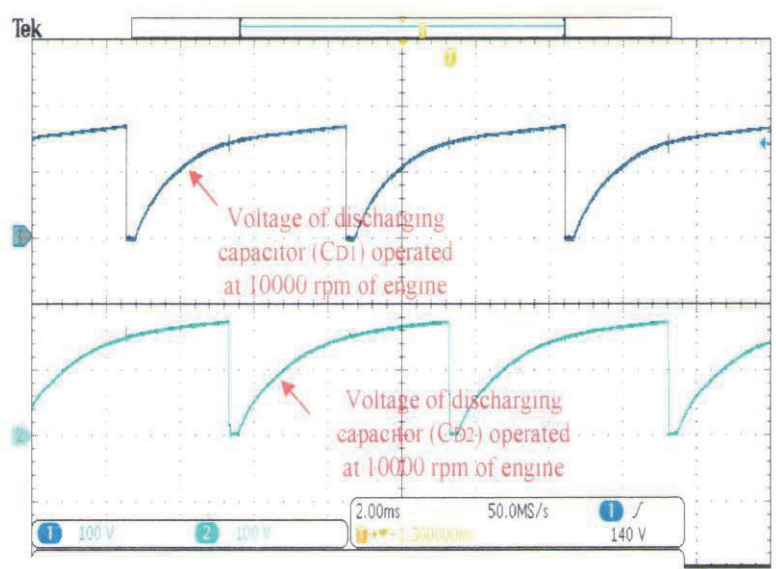

(d)

Fig. 9. (Color online) Experimental voltage waveforms of discharging capacitors $\mathrm{C}_{\mathrm{D} 1}$ and $\mathrm{C}_{\mathrm{D} 2}$ : (a) 1000, (b) 5000, (c) 7500, and (d) $10000 \mathrm{rpm}$.

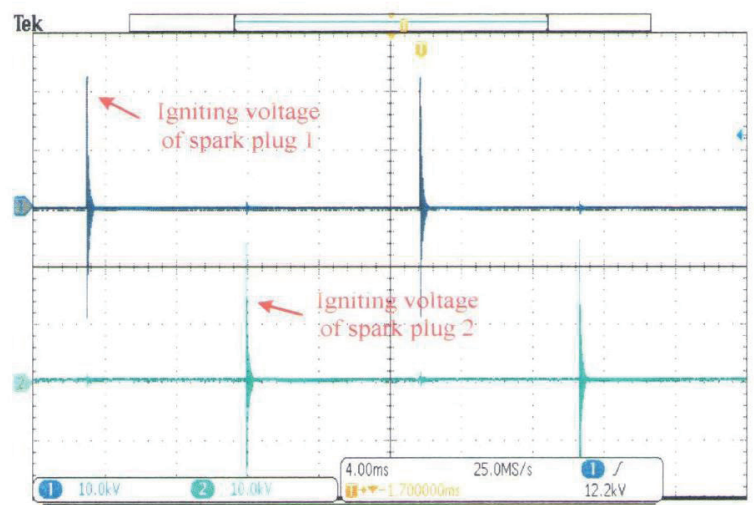

Fig. 10. (Color online) Experimental igniting voltage waveforms of spark plugs 1 and 2. 
$25 \mathrm{kV}$. Figure 11 shows extended igniting voltage waveforms of spark plugs 1 and 2. Figure 12 shows the exact igniting conditions of spark plugs 1 and 2. To verify that the proposed CDI for dual-cylinder motorcycles can reduce exhausted emission, the exhausted emissions for magnetic ignition and the proposed CDI are compared in Table 3.

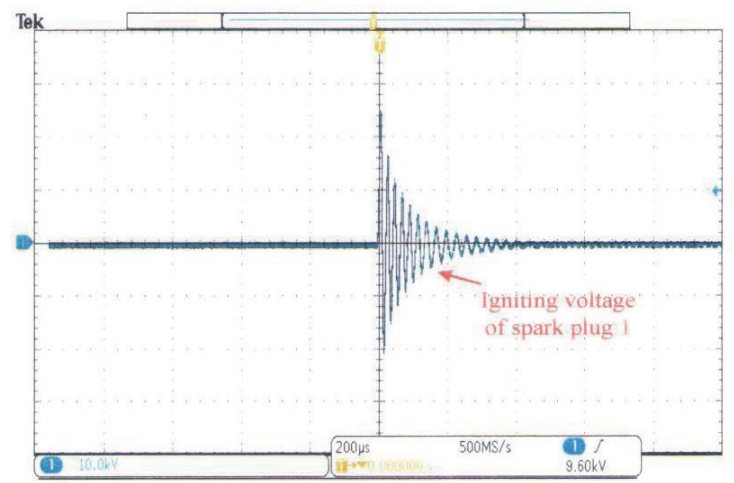

(a)

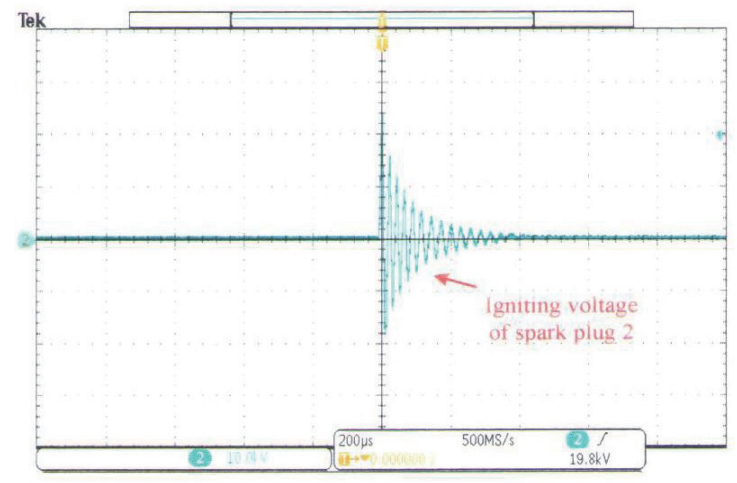

(b)

Fig.11. (Color online) Extended igniting voltage waveforms: (a) spark plug 1 and (b) spark plug 2.

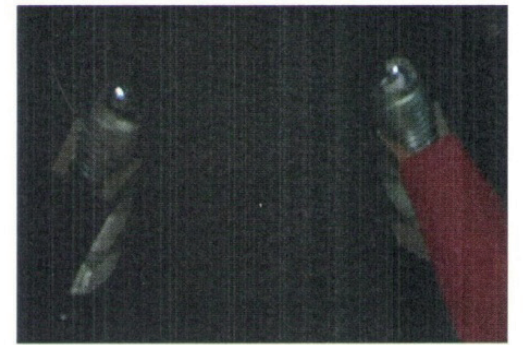

(a)

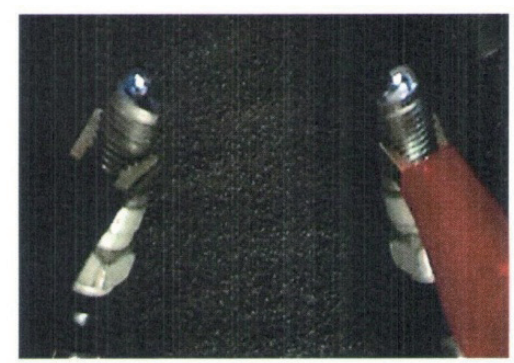

(c)

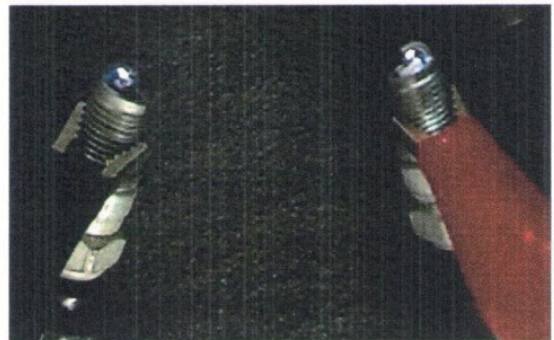

(b)

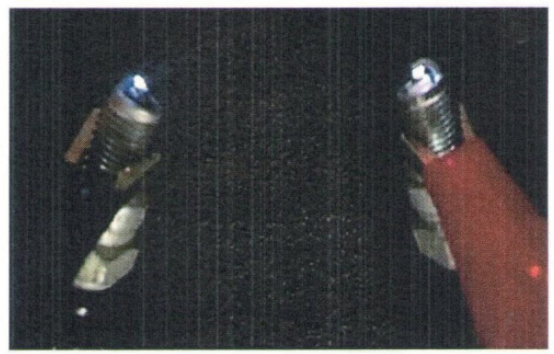

(d)

Fig. 12. (Color online) Exact ignition conditions of spark plugs 1 and 2: (a) 1000, (b) 5000, (c) 7500, and (d) 10000 rpm.

Table 3

Comparison of exhausted emission between magnetic ignition and the proposed CDI.

\begin{tabular}{|c|c|c|c|c|}
\hline \multicolumn{5}{|c|}{ Exhausted $\mathrm{HC}$ and $\mathrm{CO}$ at engine speed of $5000 \mathrm{rpm}$} \\
\hline Mag1 & ition & Pro & & Decreases \\
\hline \multicolumn{2}{|c|}{ Measurement of exhausted gas } & Measureme & austed gas & \multirow{3}{*}{$\begin{array}{r}\mathrm{HC}=41 \mathrm{ppm} \\
\mathrm{CO}=0.23 \%\end{array}$} \\
\hline $\mathrm{HC}(\mathrm{ppm})$ & 223 & $\mathrm{HC}(\mathrm{ppm})$ & 182 & \\
\hline $\mathrm{CO}(\%)$ & 1.85 & $\mathrm{CO}(\%)$ & 1.62 & \\
\hline
\end{tabular}




\section{Conclusions}

In this study, a proposed CDI for dual-cylinder motorcycles has been built and implemented. The proposed CDI mainly uses Hall sensors to sense the optimal signals of ignition times, from which the optimal ignition angles of the spark plugs can be obtained. In a comparison of exhausted emission between magnetic ignition and the proposed CDI, it was found that $\mathrm{HC}$ emission was reduced by $41 \mathrm{ppm}$ and $\mathrm{CO}$ emission was reduced by $0.23 \%$. Therefore, air pollution can be reduced and environmental quality can be improved significantly by adopting the proposed CDI. Experimental results have verified that the proposed CDI is suitable for dual-cylinder motorcycles.

\section{Acknowledgments}

This work was supported by the Ministry of Science and Technology, Taiwan, under Grant No. MOST 107-2221-E-167-018.

\section{Author Contributions}

All of the authors contributed to publishing this paper. Jye-Chau Su wrote the paper, and Cheng-Tao Tsai and Ji-Xin Chen contributed to the design of the circuit and experimental results.

\section{Conflicts of Interest}

The authors declare that there are no conflicts of interest regarding the publication of this paper.

\section{References}

1 T. D. Tsoutsos and Y. A. Stamboulis: Sci. Direct 25 (2005) 753. https://doi.org/10.1016/j.technovation.2003.12.003

2 P. Street and I. Miles: Sci. Direct 24 (1996) 413. https://doi.org/10.1016/0301-4215(96)00013-4

3 G. Yufeng and F. Zongde: Proc. Int. Conf. Computational Intelligence and Natural Computing (IEEE, 2009) 305.

4 W. D. Harris: Proc. Intersociety Energy Conversion Engineering Conf. (IEEE, 1997) 967.

5 C. Wangwiwatthana, N. Kaewraungrit, and J. Parnklang: Proc. Int. Conf. Control, Automation and Systems (IEEE, 2007) 1499.

6 A. A. Tropina, L. Lenarduzzi, S. V. Marasov, and A. P. Kuzmenko: IEEE Trans. Plasma Sci. 37 (2009) 2286. https://doi.org/10.1109/TPS.2009.2029692

7 A. Omar, N. Mariun, and I. B. Aris: Proc. SCOReD 2007. 5th Student Conf. (IEEE, 2007) 1.

8 B. Li and M. Wei: Proc. Int. Conf. Energy and Environment Technology (IEEE, 2009) 337.

9 P. Capaldi, A. Dannier, and I. Spina: IEEE Trans. Ind. Electron. 2 (2012) 374. https://doi.org/10.1109/ SPEEDAM.2012.6264623

10 J. Zhang, D. D.-C. Lu, and T. Sun: IEEE Trans. Ind. Electron. 57 (2010) 1041. https://doi.org/10.1109/ TIE.2009.2028336

11 F. A. Mohideen: Proc. Int. Conf. Industrial and Information Systems (IEEE, 2010) 275.

12 C. B. Tzeng, T. S. Wey, and T. Y. Su: Proc. ISDA 08. Eighth Int. Conf. (IEEE, 2008) 215.

13 F. J. Zhang, Y. S. Ge, Y. Huang, F. S. Liu, Y.-B. Sun, and S. J. Wu: Proc. Vehicle Electronics Conf. (IEEE, 1999) 34. 


\section{About the Authors}

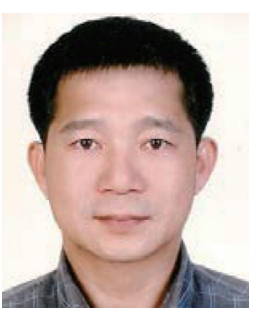

Jye-Chau Su received his B.S. degree in electric engineering from Tam Chun University, Taipei, Taiwan, in 1991, and his M.S. degree from Fairleigh Dickinson University, USA, in 1998. He is currently working toward a Ph.D. degree at the Graduate Institute of Engineering Science and Technology, National Kaohsiung University, Taiwan. His research interests include converters, inverters, and vehicle power management.

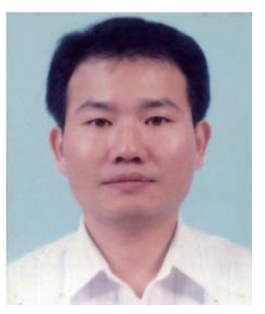

Cheng-Tao Tsai received his B.S. degree in electrical engineering from Feng Chia University, Taichung, Taiwan, in 1991, and his M.S. and Ph.D. degrees from National Chung Cheng University, Chia-Yi, Taiwan, in 2003 and 2008, respectively. Recently, he joined National Chin-Yi University of Technology, Taichung, Taiwan, where he is currently a professor in the Department of Electrical Engineering. His current research interests include the design of switching-mode power supplies, power factor correction technology, and chargers for electric vehicles.

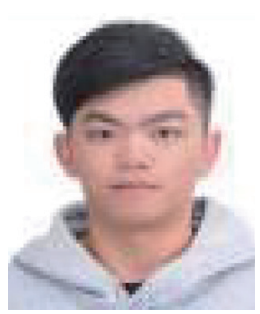

Ji-Xin Chen received his B.A. degree in electrical engineering in 2019 from National Chin-Yi University of Technology, Taiwan. His area of research is switching-mode power supplies. 